\title{
RESEARCH
}

Open Access

\section{The effects of n-6 polyunsaturated fatty acid deprivation on the inflammatory gene response to lipopolysaccharide in the mouse hippocampus}

\author{
Shoug M. Alashmali ${ }^{1,2} \mathbb{B}$, Lin Lin², Marc-Olivier Trépanier², Giulia Cisbani ${ }^{2}$ and Richard P. Bazinet ${ }^{2 *}$
}

\begin{abstract}
Background: Neuroinflammation is thought to contribute to psychiatric and neurological disorders such as major depression and Alzheimer's disease (AD). N-6 polyunsaturated fatty acids (PUFA) and molecules derived from them, including linoleic acid- and arachidonic acid-derived lipid mediators, are known to have pro-inflammatory properties in the periphery; however, this has yet to be tested in the brain. Lowering the consumption of n-6 PUFA is associated with a decreased risk of depression and AD in human observational studies. The purpose of this study was to investigate the inflammation-modulating effects of lowering dietary n-6 PUFA in the mouse hippocampus.

Methods: C57BL/6 male mice were fed either an n-6 PUFA deprived (2\% of total fatty acids) or an n-6 PUFA adequate (23\% of total fatty acids) diet from weaning to 12 weeks of age. Animals then underwent intracerebroventricular surgery, in which lipopolysaccharide (LPS) was injected into the left lateral ventricle of the brain. Hippocampi were collected at baseline and following LPS administration (1, 3, 7, and 14 days). A microarray ( $n=3$ per group) was used to identify candidate genes and results were validated by real-time PCR in a separate cohort of animals ( $n=5-8$ per group).
\end{abstract}

Results: Mice administered with LPS had significantly increased Gene Ontology categories associated with inflammation and immune responses. These effects were independent of changes in gene expression in any diet group. Results were validated for the effect of LPS treatment on astrocyte, cytokine, and chemokine markers, as well as some results of the diets on Ifrd2 and Mfsd2a expression.

Conclusions: LPS administration increases pro-inflammatory and lipid-metabolizing gene expression in the mouse hippocampus. An n-6 PUFA deprived diet modulated inflammatory gene expression by both increasing and decreasing inflammatory gene expression, without impairing the resolution of neuroinflammation following LPS administration.

Keywords: Neuroinflammation, Lipopolysaccharide, N-6 polyunsaturated fatty acids, mRNA, Hippocampus, Arachidonic acid, Linoleic acid

\footnotetext{
* Correspondence: richard.bazinet@utoronto.ca

${ }^{2}$ Department of Nutritional Sciences, Faculty of Medicine, University of

Toronto, Toronto, ON, Canada

Full list of author information is available at the end of the article
}

(c) The Author(s). 2019 Open Access This article is distributed under the terms of the Creative Commons Attribution 4.0 International License (http://creativecommons.org/licenses/by/4.0/), which permits unrestricted use, distribution, and reproduction in any medium, provided you give appropriate credit to the original author(s) and the source, provide a link to the Creative Commons license, and indicate if changes were made. The Creative Commons Public Domain Dedication waiver (http://creativecommons.org/publicdomain/zero/1.0/) applies to the data made available in this article, unless otherwise stated. 


\section{Background}

Neuroinflammation is an active defensive process characterized by many reactions including the release of arachidonic acid (ARA; n-6 PUFA), and ARA-derived proinflammatory lipid mediators, which in turn regulate inflammatory genes. Neuroinflammation is increasingly recognized as an important component, either causal or as a secondary response, of neurodegenerative diseases, including Alzheimer's disease (AD) and Parkinson's disease, as well as psychiatric disorders, such as major depression [1-3].

The brain is an immune-privileged tissue compared to the peripheral immune system, containing its typical prominent immune cells: microglia and astrocytes $[4,5]$. Microglia and astrocyte activation, pro-inflammatory cytokines such as interleukin (Il)-1, $\mathrm{Il}-6$, and tumor necrosis factor (Tnf), chemokines such as $\mathrm{Ccl} 5$, or other neuroinflammatory markers, as well as reactive oxygen species, are elevated in animal models of neuroinflammation [6-8] and in human subjects with neurological disorders [9-11].

In the brain, n-6 PUFA makes up approximately 10\% of total fatty acids $[12,13]$. ARA is the most abundant $\mathrm{n}-6$ PUFA in the brain and is involved in many functions in the central nervous system, including neurotransmission, neurogenesis, and neuroinflammation $[14,15]$. Altered n-6 PUFA metabolism has been linked to the pathogenesis of both neurological and psychiatric disorders [16-18]. Studies in humans have suggested a proinflammatory role of $\mathrm{n}-6$ PUFA in many brain disorders, such as $\mathrm{AD}$ and depression $[18,19]$. While the majority of n-6 PUFA have pro-inflammatory properties as precursors of prostaglandins and leukotrienes, some n- 6 PUFA can also be converted to anti-inflammatory mediators including lipoxins and epoxyeicosatrienoic acids (EETs) [20-23]. Because n-6 PUFA-derived lipid mediators can act as both pro- and anti-inflammatory, it is unclear how dietary n-6 PUFA modulates neuroinflammation.

Despite the fact that animal studies generally demonstrate that lowering n- 6 PUFA lowers brain ARA and ARA-derived lipid mediators $[12,13,24]$ and/or enzymes of the ARA cascade [25, 26], little is known regarding their effects on brain inflammation and its resolution. Studies have evaluated only a few proinflammatory markers at one time point [26]. The goal of this study was to examine the hippocampal response to an intracerebroventricular (icv) injection of lipopolysaccharide (LPS) over 14 days in mice consuming either an n-6 PUFA deprived or adequate diet. The administration of icv LPS is known to induce neuroinflammation by activating the toll-like receptor 4 and promoting a strong innate immune response accompanied by the secretion of pro-inflammatory cytokines and chemokines. We identified some changes in inflammation associated gene expression with dietary n-6 PUFA manipulation; however, no impairment in the resolution response to LPS was observed.

\section{Methods \\ Animals and diets}

The present experiment was carried out in accordance with the guidelines of the Canadian Council on Animal Care (protocol \# 20011827). Mice were maintained under controlled light (14/10 light/dark cycle) and temperature conditions $\left(21^{\circ} \mathrm{C}\right)$ in the Department of Comparative Medicine animal facility at the University of Toronto, with ad libitum access to food and water.

C57BL/6 male mice were purchased from Charles River Laboratories (Saint-Constant, QC, Canada) and were received at the animal facility at 2 weeks of age with their dams. After a week of acclimatization, mice were randomly weaned onto either an n-6 PUFA 23\% adequate or an n-6 PUFA 2\% deprived diet (Dyets Inc., Bethlehem, PA, USA), in which $40 \%$ of the safflower oil in n-6 PUFA adequate diet was replaced with hydrogenated coconut oil. We used "adequate" and "deprived" as relative terms to maintain consistency with the previous literature $[12,13]$ to describe the $23 \%$ and $2 \%$ of total fatty acids LA levels, respectively, in the diets. The amount of linoleic acid in n-6 PUFA deprived diet is $10 \%$ of the minimum requirement of LA for rodents based on the AIN-93 standard diet (12 mg/g, 4\% of energy) [27], but rodents do not show significant signs of LA deficiency. The level of LA in the n-6 PUFA adequate diet is comparable to the recommended level of LA for humans: 1000-1500 $\mathrm{mg}$ of linoleic acid per $100 \mathrm{~g}$ of diet, which provides $\sim 2-$ $3 \%$ of energy $[28,29]$. However, the amount of LA in the AIN-93 diet is based on the prevention of essential fatty acid deficiency for both linoleic acid and alpha-linolenic acid; therefore, the requirement of linoleic acid may have been overestimated [30].

The fatty acid compositions of the diets have been reported previously [13]. The main fatty acids in the $n-6$ PUFA adequate diet were linoleic (18:2n-6, 23.2\%), oleic (18:1n-9, 7.5\%), lauric (12:0, 26.2\%), and palmitic (16:0, $8.8 \%)$. The most abundant fatty acids as a percent of total fatty acids in the n-6 PUFA deprived diet were linoleic $(1.7 \%)$, oleic $(6 \%)$, palmitic $(9.5 \%)$, and lauric (12:0, $40.9 \%$ ). Approximately $3.5 \%$ of total fatty acids were alpha-linolenic acid in both diets. Both ARA and docosahexaenoic acid (DHA) were not detected in either diet.

\section{Intracerebroventricular administration of LPS}

At 12 weeks of age, 9 weeks after weaning, animals underwent icv surgery, in which LPS was injected into the left lateral ventricle of the brain as described previously [7]. LPS (E. coli stereotype 055:B5, Sigma Aldrich, St-Louis, MO, USA) was diluted to $1 \mu \mathrm{g}$ in $1 \mu \mathrm{l}$ of $0.9 \%$ 
of sterile saline. Briefly, mice were anesthetized, weighed, and immobilized in a stereotaxic setup with a digital reader (Stoelting, Wood Dale, IL, USA), and $150 \mu \mathrm{l}$ of $0.03 \%$ sensorcaine was injected s.c. at the incision site. Following the incision and exposing the skull, a small hole was drilled $-0.1 \mathrm{~mm}$, medial/lateral and $-0.5 \mathrm{~mm}$ anterior/posterior to the bregma. Five microliters of LPS was then injected at a depth of $-2.4 \mathrm{~mm}$ from the surface of the skull at a rate of $1 \mu \mathrm{l} / \mathrm{min}$ over $5 \mathrm{~min}$ by an electronic Stereotaxic Injector (Stoelting). The accuracy of the LPS injection to the left lateral ventricle was confirmed by periodic injection of Evan's blue dye. Animal body weights were measured, after which mice were euthanized at 1, 3, 7, and 14 days following surgeries; as described below. These time points were selected based on our recent publication [7], where the time course of activated microglia and other inflammatory markers including cytokines and chemokines detected at 3 days and returned to baseline by 14 days, and are therefore time points where inflammation and resolution is likely to be detected. Non-surgery animals were used throughout the study as a reference control. In order to minimize the number of animals required, we did not perform sham surgeries as we have previously reported that icv LPS or amyloid beta induce a stronger inflammatory response as compared to sham surgery $[8,31]$.

\section{Brain collection for RNA measurements}

For gene expression measurements, mice were euthanized by $\mathrm{CO}_{2}$ asphyxiation. Brains were rapidly harvested, and the left hippocampus (the ipsilateral side of LPS administration) was dissected and flash frozen with liquid nitrogen. Samples were stored at $-80^{\circ} \mathrm{C}$ until further use.

\section{RNA extraction}

Ipsilateral hippocampi from $\mathrm{CO}_{2}$ asphyxiated animals were homogenized in $150 \mu$ l Trizol (ThermoFisher Scientific, Waltham, MA, USA) with a Kimbel Kontes pestle homogenizer (Fisher Scientific, Waltham, MA, USA) as previously described [31]. Briefly, an additional $850 \mu \mathrm{l}$ of Trizol was added to the samples. RNA was extracted according to the manufacturer's instructions. RNA efficiency and the presence of contaminants were assessed with a Nanodrop 1000 Spectrophotometer (Nanodrop Technologies, Wilmington, DE, USA). The integrity of isolated RNA was measured in all microarray samples with BioAnalyzer Assay (Agilent 2100, Santa Clara, CA, USA); RNA integrity number values were higher than 8 .

\section{Microarray analysis}

A microarray (Affymetrix Gene ST arrays) was conducted to identify patterns of inflammatory gene expression associated with the LPS administration and diet. As previously described [31], extracted RNA was reverse transcribed with a WT Expression Kit (ThermoFisher), then single-stranded complementary DNA was fragmented and labeled according to the Affymetrix WT fragmentation and labelling protocol. cDNA was hybridized to the arrays with an Affymetrix Mouse Gene 2.0 ST GeneChip (ThermoFisher) for $18 \mathrm{~h}$ at $45^{\circ} \mathrm{C}$ at $60 \mathrm{RPM}$ to process it for analysis. Hybridization controls were similar across all arrays, indicating successful hybridization. Data was then imported into GeneSpring v13.1.1 (Agilent) for analysis. Data were normalized using a standard (for Affymetrix ST arrays) known as robust multi-array average (RMA) 16 normalization, followed by a median centred normalization per probe set. Data was filtered to remove probes with signals below the 20th percentile of the distribution of intensities for all samples. The final list contained 27,661 probe sets.

\section{Real time-qPCR}

A group of genes driving categorical enrichment, by LPS administration or diet, from the microarray were used for validating the microarray results. Gene expression was measured in the same samples that were used for the microarray analysis as well as an independent cohort of $\mathrm{CO}_{2}$ asphyxiated animals to increase the sample size. Extracted RNA was reverse transcribed using a High Capacity cDNA Reverse Transcription Kit (ThermoFisher) according to the manufacturer's instructions. Gene expression was measured using TaqMan gene expression assays (ThermoFisher) for lymphocyte antigen 6 complex, locus A (Ly6A, Mm04337234_mH), glial fibrillary acidic protein (Gfap, Mm01253033_m1) and the high affinity immunoglobulin gamma Fc region 1 (Fcgr1, Mm00438874_m1), chemokine (C-Cmotif) ligand 12 (Ccl12, Mm01617100_m1), interferon regulatory factor 7 (Irf7, Mm00516788_m1), phospholipase $\mathrm{A}_{2}$, group IVA (cytosolic, calcium-dependent) (Pla2g4a, Mm00447040_m1), chemokine (C-Cmotif) ligand 19 (Ccl19, Mm00839966_g1), interferon regulatory factor 2 (Irf2, Mm00515206_m1), interferon gamma receptor 2 (Ifngr2, Mm00492626_m1), major facilitator superfamily domain-containing protein 2 (Mfsd2a, Mm01192208_m1), Ifrd2 (Mm00518083_m1), and TaqMan Gene Expression 2X Master Mix (ThermoFisher) as per manufacturer's instructions. Each 10- $\mu$ l reaction was run in triplicate in a 384-well optical plate on a 7900 HT Real-time PCR machine (Applied Biosystems, Foster City, CA, USA) with an initial incubation at $95^{\circ} \mathrm{C}$ for $10 \mathrm{~min}$, followed by 40 cycles of $95^{\circ} \mathrm{C}$ for $15 \mathrm{~s}$ and $60^{\circ} \mathrm{C}$ for $60 \mathrm{~s}$ as described previously [32]. Results are expressed as fold change from baseline non-surgery animals, calculated by using the equation $2^{-\Delta \Delta \mathrm{Ct}}$ normalized to glyceraldehyde 3-phosphate dehydrogenase (Gapdh, Mm99999915_g1) and hypoxanthineguanine phosphoribosyltransferase (Hprt, Mm03024075 m1). Gapdh and Hprt were selected as housekeeping genes based on their stability in the microarray study 
(Additional file 1; Figure S1) and their previous use in other papers measuring similar genes [33]. The stability of Gapdh and Hprt gene expressions across the LPS surgery and diet groups was confirmed in the full results of qPCR experiment using the GeNorm command in qbase+ software version 3.1 (Biogazelle, Zwijnaarde, Belgium-www.qbaseplus. com). An average $M$ value of 0.796 was identified for Gapdh and Hprt, with $M$ values up to 1 considered as acceptable stability for animal experiments.

\section{Statistical analysis}

Body weight of animals and gene expression for the microarray validation were compared between the diet and LPS administration groups using a two-way ANOVA. Significant interactions were further analyzed by one-way ANOVA with a Tukey-Kramer post hoc test. Student's $t$ test was used to compare data between diet groups at each time point after LPS administration. Microarray data was analyzed in GeneSpring v13.1.1. Normalized expressions were analyzed via two-way ANOVA to test the effect of both LPS administration and diet and one-way ANOVA with a Tukey-Kramer post hoc test to examine the effect of LPS administration in each diet group. An unsupervised clustering was performed on genes that varied in the one-way ANOVA using a Pearson-centered correlation as a distance metric to build a hierarchical clustering heat map. The Venny online tool was used to identify overlap and unique genes between each post hoc list [34]. The results of each post hoc test was divided into positive or negative fold change $(<1.5)$, and a Benjamini and Yekutielicorrected hypergeometric test $(p<0.1)$ was used to examine Gene Ontology (GO) functional category enrichment. GO categories were considered significant if they met the false discovery rate cutoff and contained at least two probe sets per category. Similar GO results were obtained when the samples were analyzed in the Database for Annotation, Visualization and Integrated Discovery (DAVID) version 6.8, an online bioinformatics tool offered by the National Institutes of Health (https:// david.ncifcrf.gov/) [35]. A one-way ANOVA was performed on normalized expression values of genes driving categorical enrichment to examine main and interactive effects of LPS administration in each diet group. A $p$ value $<0.05$ (raw or false discovery rate corrected depending on the analysis) was considered statistically significant. The sample size was $n=7-8$ for the body weight, $n=3$ for the microarray data, and $n=5-8$ for the microarray validation.

\section{Results}

\section{Body weight}

A significant main effect of LPS administration on body weight was detected at post-surgery days 1,3 , and $7(p<$
0.05, Additional file 1; Figure S2). The n-6 PUFA deprived and adequate groups were not significantly different from one another, with both groups losing approximately an average of $3 \mathrm{~g}$. Mice fed with the n- 6 PUFA deprived diet had lower body weight versus the adequate group at post-surgery day 14, regardless of LPS administration ( $p<0.05$, Additional file 1; Figure S2).

\section{Gene expression analysis Microarray}

The full microarray data (median centered) is presented in Additional file 2 (two-way ANOVA) and Additional file 3 (one-way ANOVA). Hierarchical clustering of genes found to be altered in a one-way ANOVA of the microarray data shows that samples cluster together by their respective surgery groupings (day 1 or day 3 post-surgery) regardless of their diet, indicating strong within surgery group similarities in gene expression patterns (Fig. 1). Although the low n-6 PUFA diet did not show an overall significant effect, there was a small effect between diet groups at baseline (corrected $p$ value>0.1). Irrespective of diet, 1 day following LPS administration exhibited more clustering of increased gene expression (red) for genes related to inflammation and immune processes than day 3 post-surgery, including Fc receptor (Fcgr 1$)$ and various components of lymphocytic molecules (lymphocytic antigen 86 ( $L y 86)$ and $L y 6 a$ ), cluster of signaling protein differentiation and enzymes (signal transducer and activator of transcription 1 (Stat1), receptor transporter protein 4 (Rtp4), 2' -5' oligoadenylate synthetase-like 1 (Oasl2), ubiquitin-specific peptidase 18 (Usp18), genes related to cytokine and chemokine signaling (Irf7, Irf9), interferon-induced transmembrane protein 3 (Ifitm3), interferon-induced protein with tetratricopeptide repeats 1 (Ifit1), and Ccl12 (see Additional file 2 for the annotated cluster diagram). Similar trends of high expression of some genes such as the astrocyte marker (Gfap) complement component $1 \mathrm{q}$ sub component, beta polypeptide $(C 1 q b)$, beta- 2 microglobulin $(B 2 m)$, and a gene associated with n- 6 PUFA metabolism $\mathrm{cPLA}_{2}$, group IVA (Pla2g4a), are presented at both 1 day and 3 days after LPS administration (see Additional file 2 for the annotated cluster diagram). Other genes such as colony stimulating factor 1 receptor (Csfr1), a component of immunoglobulin molecules (immunoglobulin heavy constant mu $(\mathrm{Ighm})$ ), and triggering receptor expressed on myeloid cells 2 (Trem2) are exclusively highly expressed at post-surgery day 3 . The same genes appeared to be unchanged or downregulated in the non-surgery groups for the $n-6$ PUFA deprived and adequate fed animals.

LPS administered ( 1 day or 3 days post-surgery) and non-surgery animals within the n-6 PUFA deprived and adequate groups were compared post hoc following a 


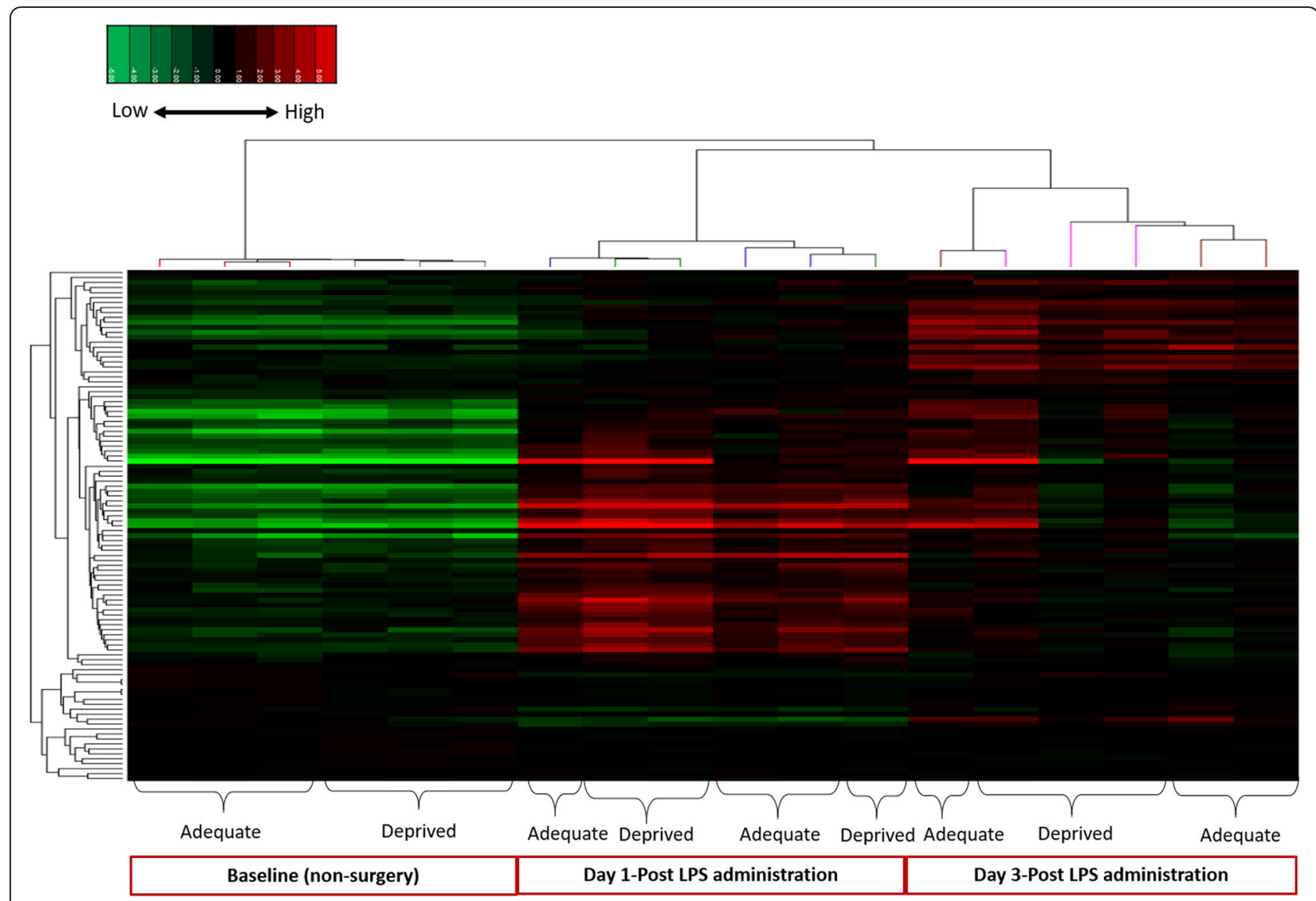

Fig. 1 Hierarchical cluster of genes significantly increased in the one-way ANOVA (uncorrected $p<0.05$, corrected $p<0.1$ ). This clustering is zoomed in on key regions of clustering with labeled branches corresponding to individual samples; a clear separation is seen between baseline (non-surgery) and days after LPS administration. We scaled the expression intensities on rows (probe sets/genes) to make them weigh equally in the clustering. The colors of the heatmap are mapped linearly low expression in green and high expression in red. Adequate: $\mathrm{n}-6$ PUFA adequate diet, deprived: $\mathrm{n}-6$ PUFA deprived diet. $n=3$ mice per group

one-way ANOVA to identify genes modified in response to the surgery in each diet group. After exclusion of unindexed predicted genes, there were 32 overlapping probe sets altered by LPS administration between $n-6$ PUFA deprived and adequate groups at day 1 and 22 overlapping probes at day 3 following LPS administration. There were very few differently expressed genes between non-surgery and LPS-administered animals, with only four genes in the $n-6$ PUFA adequate, three in the n-6 PUFA deprived group at day 1 , four genes in the $n-6$ PUFA adequate, and five in the n-6 PUFA deprived fed animals at day 3 (Fig. 2a, b, see Additional file 1 Tables S1 A and B for full gene lists). The majority of the shared genes, such as Gfap, Ccl12, Irf7, Ly6a, and Fcgr1, appeared to be more functionally important for response to LPS either at day 1 or day 3 in comparison to the ones that are exclusive to each diet. While Aif1 (iba1), $C d 86$, and $C d 68$, as markers of the microglia, and $C c l 5$, a chemokine marker, were not significantly changed in the LPS-administered animals according to corrected $p$ value of the microarray data (see Additional file 1, Figure S3), $C d 86, C d 68$, and $C c l 5$ are highly expressed in response to LPS administration when considering the raw $p$ value. Moreover, other inflammatory markers such as Il-1 $\beta$, Il-6, Tnfa, and cyclooxygenase 2 (Cox-2; Ptgs 2 ) did not show significant changes in response to LPS (see Additional file 1, Figure S3), when using either a corrected or raw $p$ value. GO analysis was applied to the list of genes altered by LPS administration in each diet group to look for functional categories of gene expression altered in response to the day 1 and day 3 postsurgery. According to the post hoc comparison, the differences in genes between the n- 6 PUFA adequate and deprived groups did not reach statistical significance and did not meet the fold change cutoff (more than 1.5) for GO analysis. Therefore, there was no categorical enrichment in response to diet.

The majority of the genes altered in response to LPS administration (day 1 and day 3) clustered significantly into functional categories after the false discovery rate 


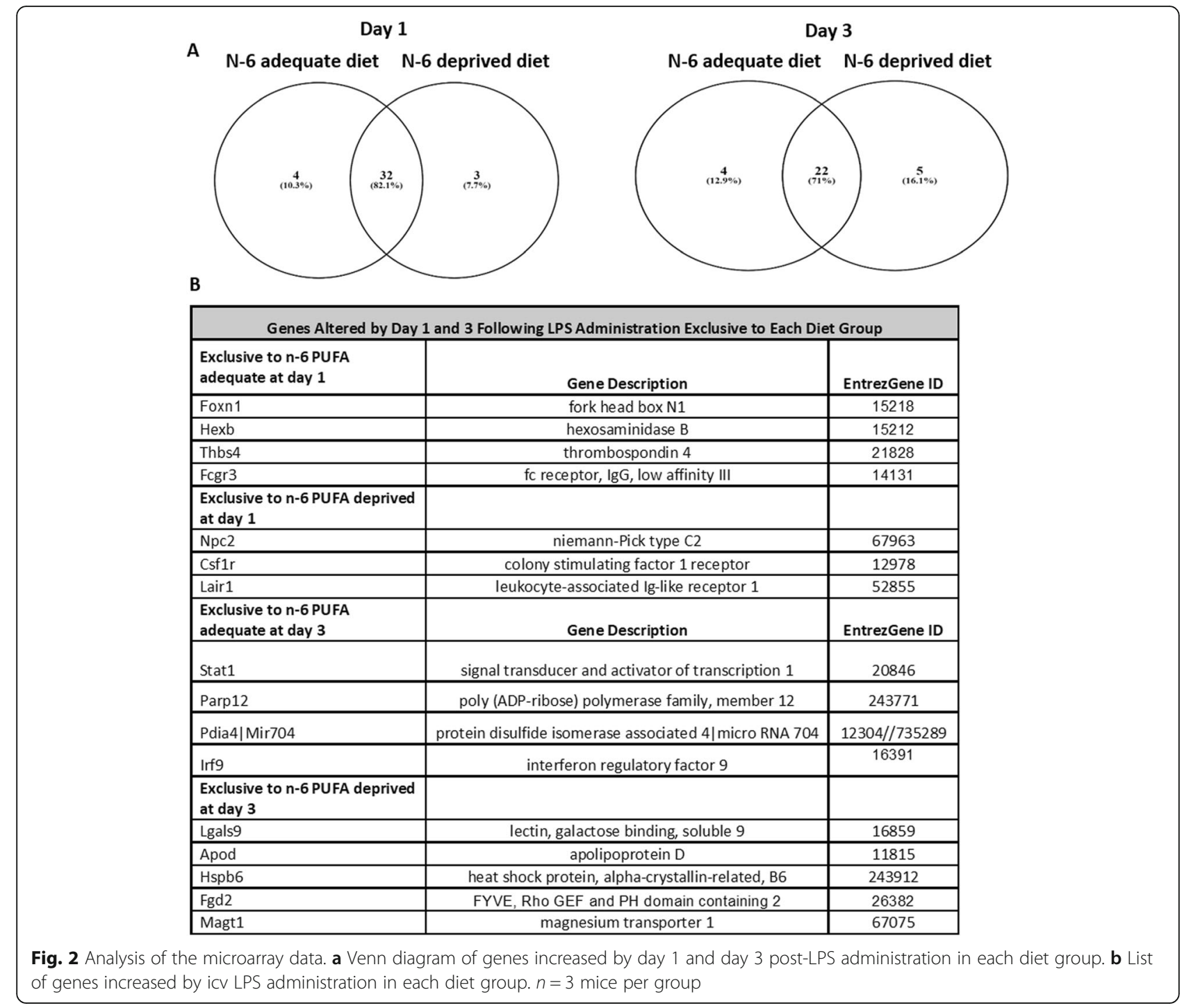

correction in each diet group (Table $1 \mathrm{~A}$ and B for day 1 post-LPS administration, see Additional file 1 Tables S2 A and $\mathrm{B}$ for day 3 post-LPS administration). However, none of the exclusive genes, except for the Stat1 gene that represents immune response enrichment, in the n-6 PUFA adequate or deprived group clustered significantly into functional categories after either raw or corrected $p$ value. At day 1 postsurgery, the majority of the significant functional enrichments $(\sim 75 \%)$ were related to immune system activation, such as antigen processing and presentation of peptide antigen, immunoglobulin-mediated immune response, or regulation of immune system process, while only about $30 \%$ of the enrichment was seen at day 3 of post-LPS administration was involved in immune- and inflammatory-related processes. Most of the remaining categories at each time point after LPS administration are parent categories upstream of immune-related categories, such as response to external stimulus or defense response.
Increased expression of 16 and 13 genes drove this categorical enrichment at day 1 of LPS administration in the n-6 PUFA deprived and adequate groups, respectively, with 12 genes overlapping, while 13 genes (10 overlapped) were involved at day 3 post-surgery for each diet (Fig. 3a, b). Many of those genes are highlighted in the hierarchical cluster analysis: Gfap (Fig. 4a), Ccl12 (Fig. 4b), Irf7 (Fig. 4c), Ifitm3 (Fig. 4d), Ly6a (Fig. 4e), Fcgr1 (Fig. 4f), Fc receptor, IgG, low affinity III (Fig. 4g, Fcgr3), Stat1 (Fig. 4h), lectin, galactose binding, soluble 9 (Fig. 4i, Lgals9), B2m (Fig. 4j), complement component 1 q sub component, alpha polypeptide (Fig. 4k, C1qa), C1qb (Fig. 4l), Trem2 (Fig. 4m), Csf1r (Fig. 4n), angiogenin, 5|ribonuclease, RNase A family 4 (Fig. 4o, Ang $\mid$ Rnase4), cathepsin S (Fig. 4p, Ctss), apolipoprotein D (Fig. 4q, Apod), Ighm (Fig. 4r), MHC ll: major histocompatibility 2, Q region locus 5 (Fig. 4s, H2-Q5), hydroxyacyl-Coenzyme A dehydrogenase/3-ketoacyl- 
Table 1 List of significantly enriched Gene Ontology categories in (A) n-6 PUFA adequate and (B) n-6 PUFA deprived at day 1 LPSadministered mice compared to non-surgery mice

\begin{tabular}{|c|c|c|c|c|c|}
\hline GO term & $\begin{array}{l}\text { BY-corrected } \\
p \text { value }\end{array}$ & $\begin{array}{l}\text { No. of genes } \\
\text { driving enrichment }\end{array}$ & GO term & $\begin{array}{l}\text { BY-corrected } \\
p \text { value }\end{array}$ & $\begin{array}{l}\text { No. of genes } \\
\text { driving enrichment }\end{array}$ \\
\hline \multicolumn{6}{|c|}{ A. Significantly enriched GO categories in n-6 PUFA adequate at baseline (non-surgery) vs day 1 LPS-administered mice } \\
\hline Immune response & $1.18 \mathrm{E}-06$ & 11 & Regulation of immune response & 0.05 & 5 \\
\hline Innate immune response & $1.18 \mathrm{E}-06$ & 9 & $\begin{array}{l}\text { Regulation of adaptive immune response based on } \\
\text { somatic recombination of immune receptors built from } \\
\text { immunoglobulin superfamily domains }\end{array}$ & 0.05 & 3 \\
\hline Immune system process & $2.12 \mathrm{E}-05$ & 12 & Immunoglobulin-mediated immune response & 0.05 & 3 \\
\hline $\begin{array}{l}\text { Cellular response to type I } \\
\text { interferon }\end{array}$ & $1.90 \mathrm{E}-04$ & 3 & Negative regulation of neuron projection development & 0.05 & 3 \\
\hline $\begin{array}{l}\text { Type I interferon signaling } \\
\text { pathway }\end{array}$ & $1.90 \mathrm{E}-04$ & 3 & B cell-mediated immunity & 0.05 & 3 \\
\hline Defense response & $3.52 \mathrm{E}-04$ & 9 & Regulation of adaptive immune response & 0.06 & 3 \\
\hline $\begin{array}{l}\text { Response to type I } \\
\text { interferon }\end{array}$ & $3.75 \mathrm{E}-04$ & 3 & Regulation of response to stimulus & 0.06 & 10 \\
\hline $\begin{array}{l}\text { Antigen processing and } \\
\text { presentation of peptide } \\
\text { antigen }\end{array}$ & $7.9 \mathrm{E}-04$ & 4 & Defense response to virus & 0.06 & 3 \\
\hline Immune effector process & $1.84 \mathrm{E}-03$ & 6 & Extracellular space & 0.06 & 7 \\
\hline Response to stress & $1.84 \mathrm{E}-03$ & 12 & Viral process & 0.06 & 4 \\
\hline Glycoprotein binding & 2.67E-03 & 4 & Multi-organism cellular process & 0.06 & 4 \\
\hline $\begin{array}{l}\text { Neuron projection } \\
\text { regeneration }\end{array}$ & $2.67 \mathrm{E}-03$ & 3 & Negative regulation of cell projection organization & 0.07 & 3 \\
\hline $\begin{array}{l}\text { Response to interferon- } \\
\text { beta }\end{array}$ & $4.35 \mathrm{E}-03$ & 3 & Regulation of immune effector process & 0.07 & 4 \\
\hline $\begin{array}{l}\text { Antigen processing and } \\
\text { presentation }\end{array}$ & $5.28 \mathrm{E}-03$ & 4 & Regulation of leukocyte mediated immunity & 0.08 & 3 \\
\hline $\begin{array}{l}\text { Response to external } \\
\text { biotic stimulus }\end{array}$ & $5.46 \mathrm{E}-03$ & 7 & Extracellular matrix organization & 0.08 & 3 \\
\hline $\begin{array}{l}\text { Response to other } \\
\text { organism }\end{array}$ & $5.46 \mathrm{E}-03$ & 7 & Extracellular structure organization & 0.08 & 3 \\
\hline $\begin{array}{l}\text { Response to biotic } \\
\text { stimulus }\end{array}$ & $6.68 \mathrm{E}-03$ & 7 & Regeneration & 0.08 & 3 \\
\hline $\begin{array}{l}\text { Antigen processing and } \\
\text { presentation of peptide } \\
\text { antigen via MHC class I }\end{array}$ & 0.01 & 3 & Negative regulation of cytokine production & 0.08 & 3 \\
\hline $\begin{array}{l}\text { Regulation of multi- } \\
\text { organism process }\end{array}$ & 0.01 & 5 & Lymphocyte-mediated immunity & 0.08 & 3 \\
\hline Response to stimulus & 0.01 & 17 & $\begin{array}{l}\text { Adaptive immune response based on somatic } \\
\text { recombination of immune receptors built from } \\
\text { immunoglobulin superfamily domains }\end{array}$ & 0.08 & 3 \\
\hline $\begin{array}{l}\text { Regulation of response to } \\
\text { external stimulus }\end{array}$ & 0.01 & 6 & Positive regulation of immune system process & 0.08 & 5 \\
\hline $\begin{array}{l}\text { Negative regulation of } \\
\text { multicellular organismal } \\
\text { process }\end{array}$ & 0.01 & 7 & Regulation of response to biotic stimulus & 0.08 & 3 \\
\hline Response to virus & 0.01 & 4 & Humoral immune response & 0.08 & 3 \\
\hline $\begin{array}{l}\text { Positive regulation of } \\
\text { immune response }\end{array}$ & 0.01 & 5 & Symbiosis, encompassing mutualism through parasitism & 0.08 & 4 \\
\hline $\begin{array}{l}\text { Defense response to other } \\
\text { organism }\end{array}$ & 0.02 & 5 & Interspecies interaction between organisms & 0.08 & 4 \\
\hline $\begin{array}{l}\text { Regulation of immune } \\
\text { system process }\end{array}$ & 0.02 & 7 & Positive regulation of response to stimulus & 0.08 & 7 \\
\hline $\begin{array}{l}\text { Positive regulation of } \\
\text { response to external } \\
\text { stimulus }\end{array}$ & 0.02 & 4 & Protein complex binding & 0.08 & 5 \\
\hline
\end{tabular}


Table 1 List of significantly enriched Gene Ontology categories in (A) n-6 PUFA adequate and (B) n-6 PUFA deprived at day 1 LPSadministered mice compared to non-surgery mice (Continued)

\begin{tabular}{|c|c|c|c|c|c|}
\hline GO term & $\begin{array}{l}\text { BY-corrected } \\
p \text { value }\end{array}$ & $\begin{array}{l}\text { No. of genes } \\
\text { driving enrichment }\end{array}$ & GO term & $\begin{array}{l}\text { BY-corrected } \\
p \text { value }\end{array}$ & $\begin{array}{l}\text { No. of genes } \\
\text { driving enrichment }\end{array}$ \\
\hline $\begin{array}{l}\text { Regulation of } \\
\text { inflammatory response }\end{array}$ & 0.02 & 4 & Regulation of localization & 0.09 & 8 \\
\hline $\begin{array}{l}\text { Regulation of defense } \\
\text { response }\end{array}$ & 0.03 & 5 & Leukocyte-mediated immunity & 0.09 & 3 \\
\hline Regulation of transport & 0.03 & 8 & Response to external stimulus & 0.09 & 7 \\
\hline $\begin{array}{l}\text { Negative regulation of } \\
\text { cellular component } \\
\text { organization }\end{array}$ & 0.04 & 5 & Negative regulation of neuron differentiation & 0.09 & 3 \\
\hline $\begin{array}{l}\text { Adaptive immune } \\
\text { response }\end{array}$ & 0.04 & 4 & Negative regulation of protein transport & 0.09 & 3 \\
\hline $\begin{array}{l}\text { Regulation of lymphocyte } \\
\text { mediated immunity }\end{array}$ & 0.05 & 3 & & & \\
\hline \multicolumn{6}{|c|}{ B. Significantly enriched GO categories in deprived n-6 PUFA at baseline (non-surgery) vs day 1 LPS-administered mice } \\
\hline Innate immune response & $5.95 \mathrm{E}-08$ & 11 & Regulation of defense response & 0.02 & 6 \\
\hline Immune response & $9.19 \mathrm{E}-08$ & 13 & $\begin{array}{l}\text { Antigen processing and presentation of peptide antigen } \\
\text { via MHC class I }\end{array}$ & 0.02 & 3 \\
\hline Immune system process & $6.45 \mathrm{E}-07$ & 15 & Lymphocyte-mediated immunity & 0.02 & 4 \\
\hline Defense response & $5.82 \mathrm{E}-05$ & 11 & $\begin{array}{l}\text { Adaptive immune response based on somatic } \\
\text { recombination of immune receptors built from } \\
\text { immunoglobulin superfamily domains }\end{array}$ & 0.02 & 4 \\
\hline $\begin{array}{l}\text { Type I interferon signaling } \\
\text { pathway }\end{array}$ & 4.14E-04 & 3 & Response to stimulus & 0.02 & 20 \\
\hline $\begin{array}{l}\text { Cellular response to type I } \\
\text { interferon }\end{array}$ & $4.14 \mathrm{E}-04$ & 3 & Regulation of immune response & 0.03 & 6 \\
\hline Immune effector process & $9.36 \mathrm{E}-04$ & 7 & Regulation of multi-organism process & 0.03 & 5 \\
\hline $\begin{array}{l}\text { Response to type I } \\
\text { interferon }\end{array}$ & $9.36 \mathrm{E}-04$ & 3 & Response to virus & 0.03 & 4 \\
\hline Response to stress & $2.01 \mathrm{E}-03$ & 14 & Response to interferon gamma & 0.03 & 3 \\
\hline $\begin{array}{l}\text { Antigen processing and } \\
\text { presentation of peptide } \\
\text { antigen }\end{array}$ & $2.01 \mathrm{E}-03$ & 4 & Leukocyte-mediated immunity & 0.03 & 4 \\
\hline $\begin{array}{l}\text { Regulation of immune } \\
\text { system process }\end{array}$ & $6.05 \mathrm{E}-03$ & 9 & Positive regulation of defense response & 0.04 & 4 \\
\hline $\begin{array}{l}\text { Neuron projection } \\
\text { regeneration }\end{array}$ & $6.05 \mathrm{E}-03$ & 3 & Positive regulation of response to stimulus & 0.04 & 9 \\
\hline $\begin{array}{l}\text { Response to external } \\
\text { biotic stimulus }\end{array}$ & $6.05 \mathrm{E}-03$ & 8 & Regulation of transport & 0.04 & 9 \\
\hline $\begin{array}{l}\text { Response to other } \\
\text { organism }\end{array}$ & $6.05 \mathrm{E}-03$ & 8 & Defense response to other organism & 0.04 & 5 \\
\hline $\begin{array}{l}\text { Response to biotic } \\
\text { stimulus }\end{array}$ & $6.78 \mathrm{E}-03$ & 8 & Regulation of response to stimulus & 0.04 & 12 \\
\hline Glycoprotein binding & $7.16 \mathrm{E}-03$ & 4 & Positive regulation of response to external stimulus & 0.05 & 4 \\
\hline $\begin{array}{l}\text { Positive regulation of } \\
\text { immune response }\end{array}$ & $7.40 \mathrm{E}-03$ & 6 & Regulation of inflammatory response & 0.05 & 4 \\
\hline $\begin{array}{l}\text { Regulation of response to } \\
\text { external stimulus }\end{array}$ & 7.65E-03 & 7 & Negative regulation of multicellular organismal process & 0.05 & 7 \\
\hline $\begin{array}{l}\text { Response to interferon- } \\
\text { beta }\end{array}$ & $7.65 \mathrm{E}-03$ & 3 & G protein-coupled receptor binding & 0.06 & 4 \\
\hline $\begin{array}{l}\text { Regulation of lymphocyte } \\
\text { migration }\end{array}$ & 7.65E-03 & 3 & Regulation of cytokine production & 0.06 & 5 \\
\hline $\begin{array}{l}\text { Immunoglobulin- } \\
\text { mediated immune } \\
\text { response }\end{array}$ & $8.89 \mathrm{E}-03$ & 4 & Extracellular space & 0.07 & 8 \\
\hline B cell-mediated immunity & $9.05 E-03$ & 4 & Regulation of lymphocyte-mediated immunity & 0.08 & 3 \\
\hline
\end{tabular}


Table 1 List of significantly enriched Gene Ontology categories in (A) n-6 PUFA adequate and (B) n-6 PUFA deprived at day 1 LPSadministered mice compared to non-surgery mice (Continued)

\begin{tabular}{|c|c|c|c|c|c|}
\hline GO term & $\begin{array}{l}\text { BY-corrected } \\
p \text { value }\end{array}$ & $\begin{array}{l}\text { No. of genes } \\
\text { driving enrichment }\end{array}$ & GO term & $\begin{array}{l}\text { BY-corrected } \\
p \text { value }\end{array}$ & $\begin{array}{l}\text { No. of genes } \\
\text { driving enrichment }\end{array}$ \\
\hline $\begin{array}{l}\text { Antigen processing and } \\
\text { presentation }\end{array}$ & 0.01 & 4 & Cytokine-mediated signaling pathway & 0.08 & 4 \\
\hline $\begin{array}{l}\text { Regulation of adaptive } \\
\text { immune response }\end{array}$ & 0.01 & 4 & $\begin{array}{l}\text { Regulation of adaptive immune response based on } \\
\text { somatic recombination of immune receptors built from } \\
\text { immunoglobulin superfamily domains }\end{array}$ & 0.08 & 3 \\
\hline $\begin{array}{l}\text { Positive regulation of } \\
\text { immune system process }\end{array}$ & 0.01 & 7 & Negative regulation of cellular component organization & 0.08 & 5 \\
\hline \multirow{2}{*}{$\begin{array}{l}\text { Adaptive immune } \\
\text { response }\end{array}$} & 0.01 & 5 & Negative regulation of neuron projection development & 0.09 & 3 \\
\hline & & & Regulation of multicellular organismal process & 0.10 & 10 \\
\hline
\end{tabular}

Based on $n=3$ mice per group

BY Benjamini Yekutieli false discovery rate, GO Gene Ontology

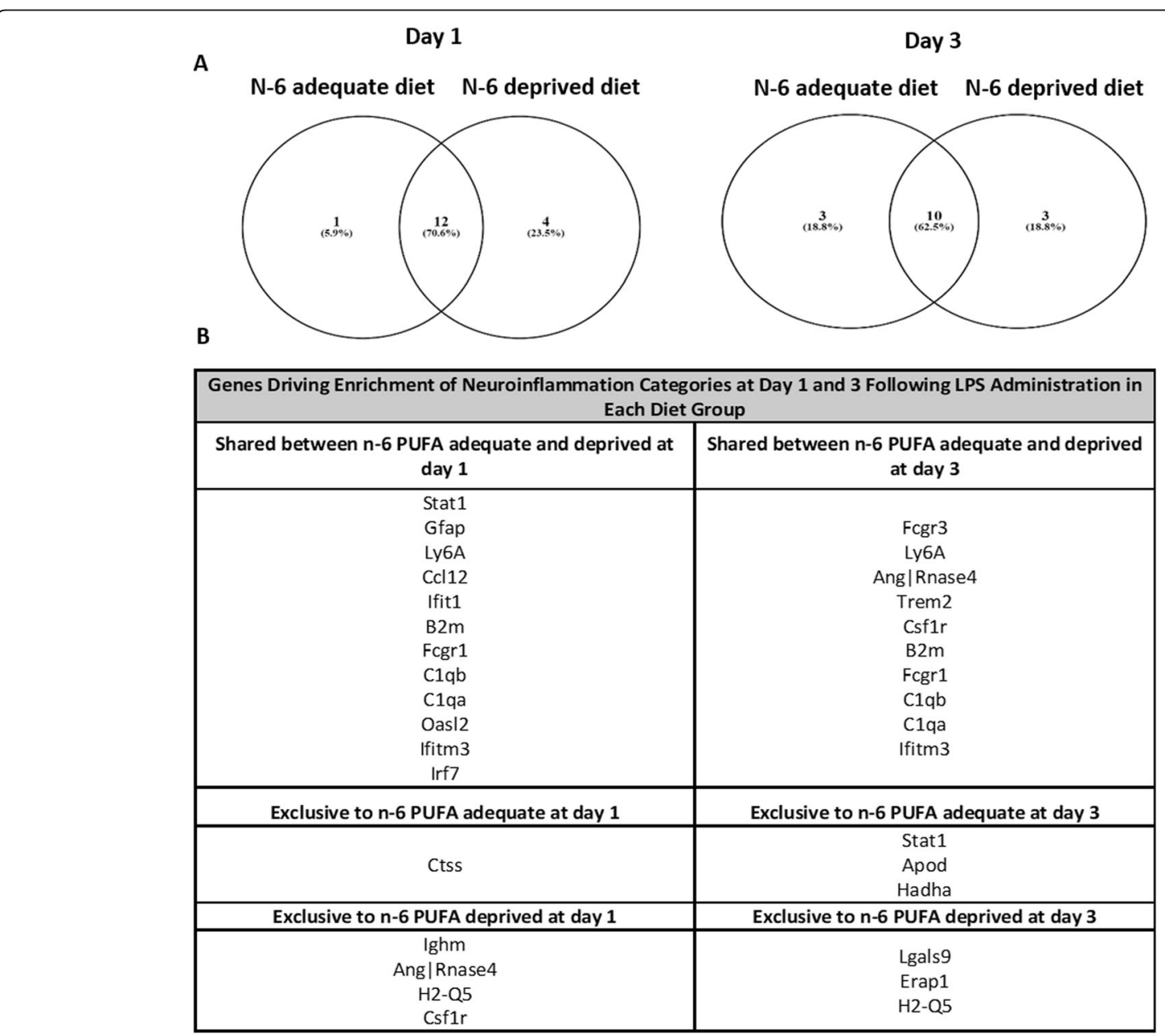

Fig. 3 Analysis of Gene Ontology. a Venn diagram of genes driving enrichment of inflammation categories. $\mathbf{b}$ List of genes driving enrichment of inflammation-associated gene expression categories at day 1 and day 3 post-LPS administration in each diet group. $n=3$ mice per group 


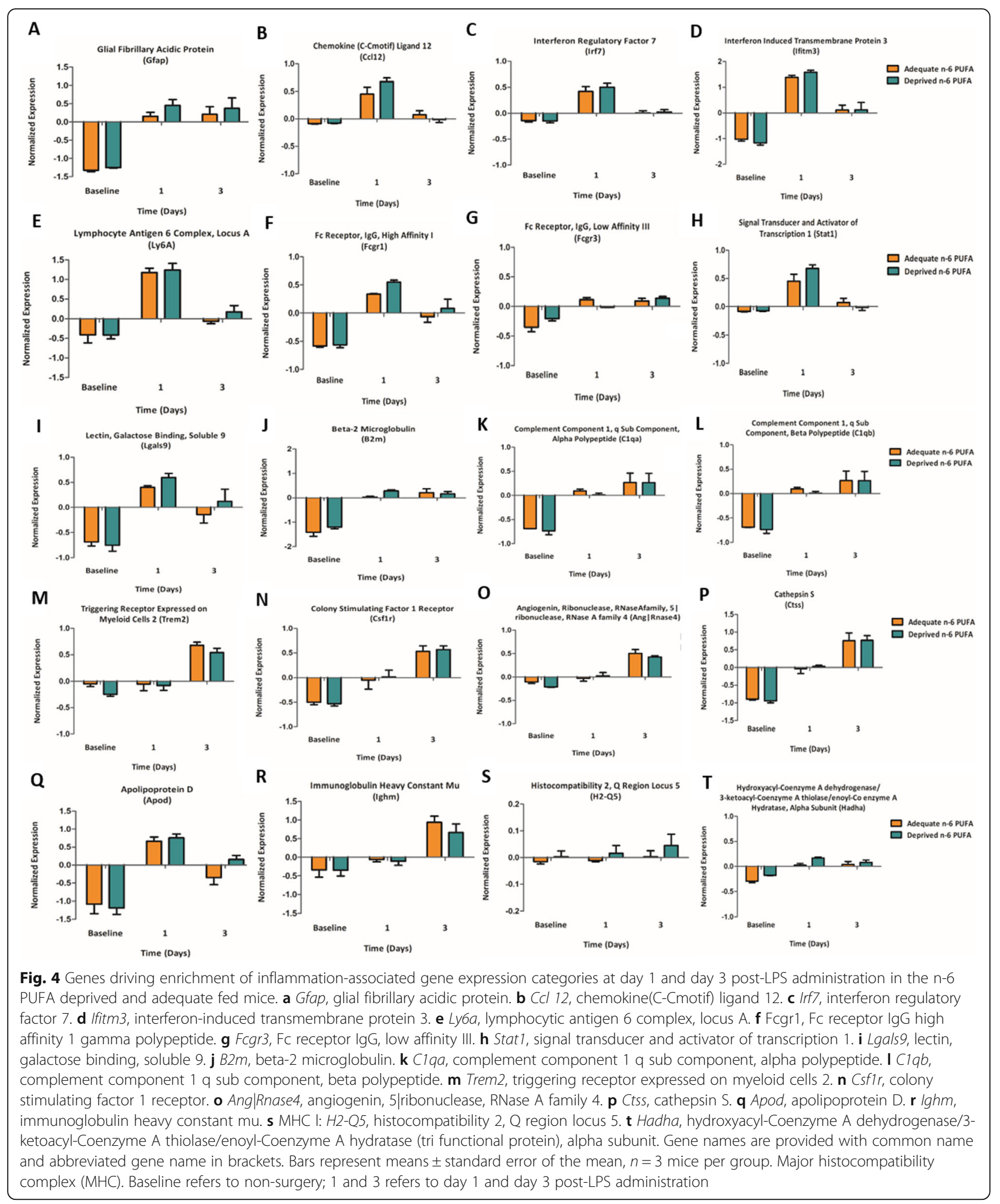

Coenzyme A thiolase/enoyl-Coenzyme A hydratase (tri functional protein), and alpha subunit (Fig. 4t, Hadha). ${ }_{\text {cPLA }}$, a gene involved in n-6 PUFA metabolism, is also one of the genes that were identified in the hierarchical map; however, it did not drive any categorical enrichment between non-surgery and LPS administration groups. All $p$ values for individual genes remained significant after the false discovery rate correction. Post 
hoc tests for all genes revealed higher expression in the LPS-administered mice than non-surgery animals at both time points, regardless of diet group (Fig. 4).

Although gene expression was not significantly different between any of the diet groups following two- and one-way ANOVA (considering either raw or corrected $p$ value), it was of interest to conduct an exploratory analysis of the candidate genes in response to the n- 6 PUFA deprived versus adequate diet using Student's $t$ test of microarray data at baseline, day 1 , and day 3 (see Additional file 4). The genes with a cutoff raw (uncorrected) $p$ value of $<0.01$, such as Ccl19, Ifrd2, Ifngr 2 , Irf2, and $M f_{s} d 2 a$, were identified and validated by qPCR. Comparison of the normalized expression of these genes between diet groups with an uncorrected $t$ test identified significant diet effects for many genes involved in inflammatory and immune processes at baseline (non-surgery), day 1 , or day 3 post-surgery (Fig. 5). The expression of other common inflammation-associated genes of microglia, cytokines, and chemokine markers, such as Aif1, Cd86, Cxcl11, and Il-6ra and genes involved in the synthesis of n-6 PUFA pro-inflammatory mediators (arachidonate 15 lipoxygenase, Alox15), were changed in response to an n-6 PUFA deprived diet; however, they did not meet the raw (uncorrected) $p$ value cutoff of $<0.01$ and thus were not used for validation (Additional file 4).

\section{Microarray validation}

To validate the Gene Ontology results for LPS surgery, expression of Fcgr1, Gfap, Irf7, Ly6a, Ccl12, and Pla2g4a was measured by RT-qPCR at days $1,3,7$, and 14 postLPS administration, as we were interested in the time course of genes expressions and in an independent cohort of non-surgery animals. When normalized to baseline (non-surgery) via the relative expression $2^{-\Delta \Delta C t}$, LPS-administered animals exhibited increased expression of all the previous genes compared to non-surgery mice at days 1 and 3 (Fig. 6), confirming and extending the microarray results. Some gene expressions, including Irf7 (Fig. 6c), Ly6a (Fig. 6d), and cPLA $_{2}$ (Pla2g4a) (Fig. 6f), appear to be decreased at 7 days while Fcgr1

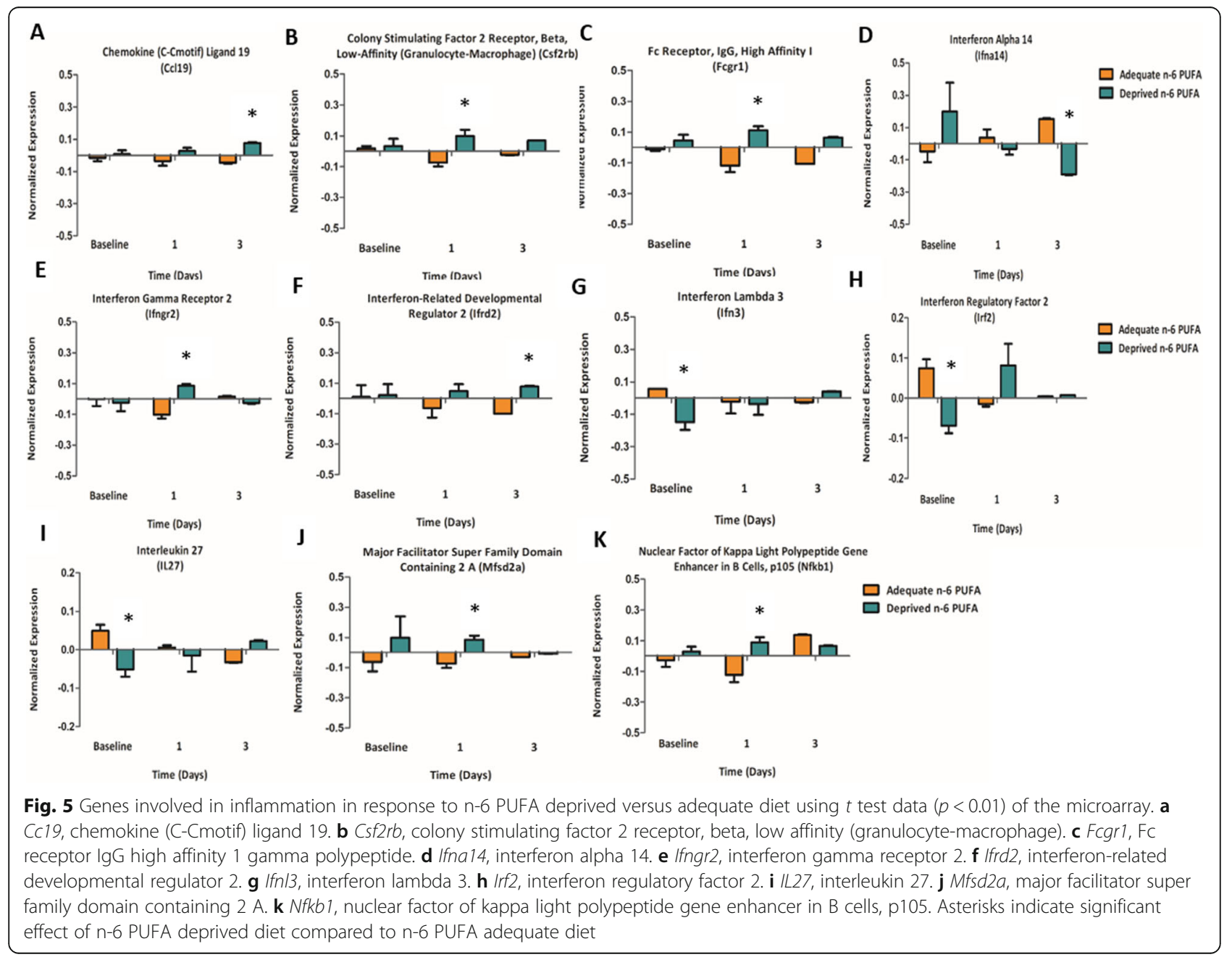




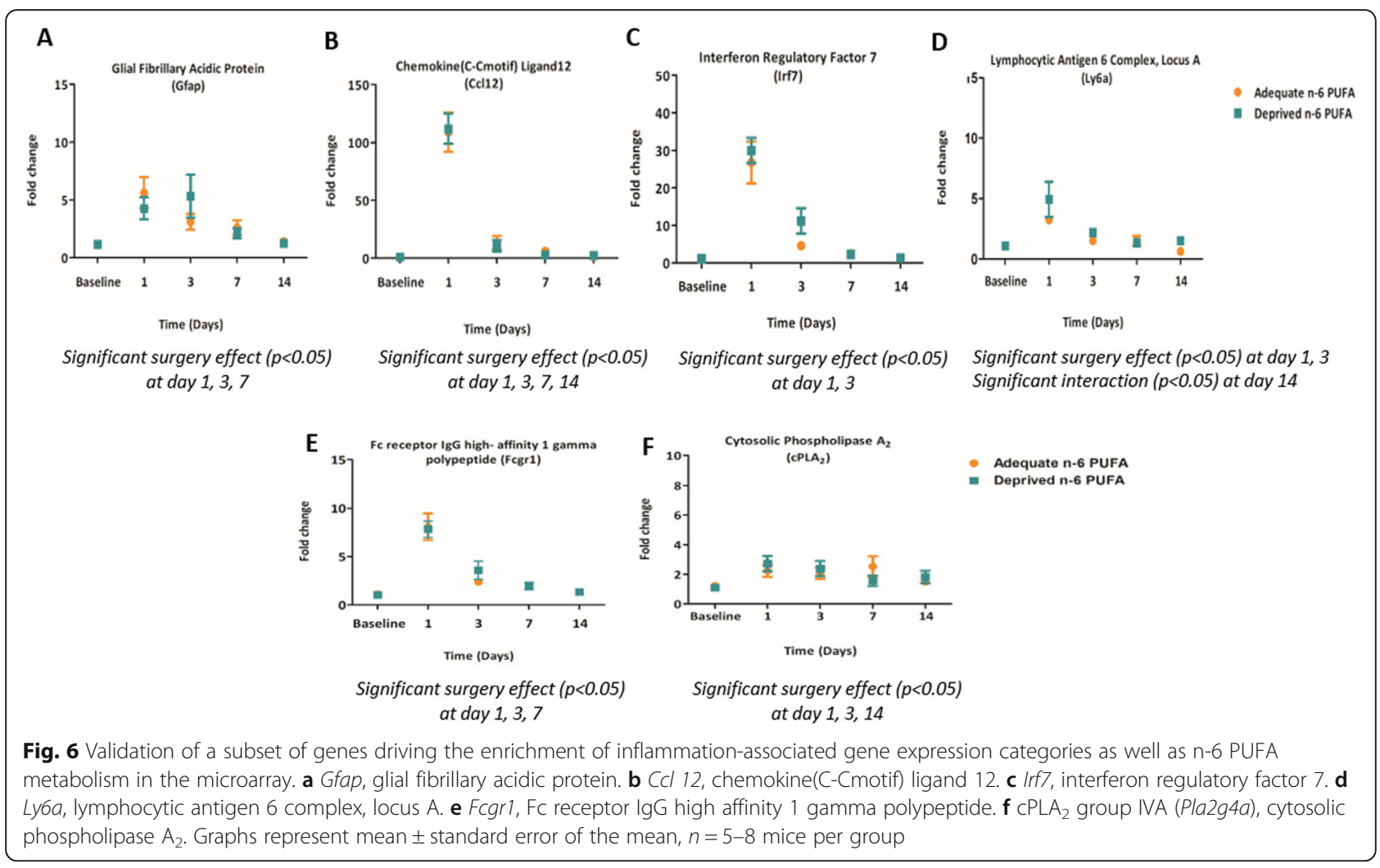

(Fig. 6e) and Gfap (Fig. 6a) decreased at 14 days following LPS administration in comparison to nonsurgery animals. However, Ccl12 (Fig. 6b) expression remained to be elevated at all time points post-LPS administration. While not being affected by LPS surgery at day 14, Ly6a signal appears to be upregulated in the n-6 PUFA deprived versus adequate fed animals $(p=0.005)$. Interestingly, Irf7 and Ly6a, cytokine and immune cell markers, respectively, were also elevated in the n-6 PUFA deprived in comparison to n-6 PUFA adequate at day 3 and day 14, respectively, using a $t$ test.

To validate the uncorrected $t$ test results in response to diet, expression of the five genes, Ccl19, Irf2, Ifrd2, Ifngr 2 , and $M f s d 2 a$, were measured at the same time points following LPS administration in both diet treatments (Fig. 7). Comparison of the gene expression between the LPS administration and diet groups via twoway ANOVA identified that $C c l 19$ and Ifrd2, chemokine and cytokine markers, expressions were increased at day 1, and day 7 for Ccl19 only, following LPS administration. Similarly, $M f s d 2 a$ was also elevated at day 1 and day 3 after LPS administration. Moreover, $M f_{s} d 2 a$ was decreased at day 1 and increased at day 3 in the n- 6 PUFA deprived versus adequate group.

Microarray validation did not confirm inflammatory expression in response to the n-6 PUFA deprived diet (Fig. 7). Contrary to the microarray uncorrected $t$ test results, the genes were not significantly higher in the animals fed n-6 PUFA deprived diet versus n-6 PUFA adequate diet either at baseline, day 1 , and/or day 3 , except for Ifrd2 (Fig. 7c, $p<0.05$ ) and Mfsd2a (Fig. 7e, $p<0.05$ ). Ifrd 2 and $M f s d 2 a$ had lower expression in response to $\mathrm{n}$ 6 PUFA deprived diet at day 1 after surgery. However, $M f s d 2 a$ was significantly increased in the n-6 PUFA deprived at day 3 post-LPS surgery. There was also a decrease in the expression of $\operatorname{Irf} 2$ (Fig. $7 \mathrm{~d}$ ) at day 1 ( $p=$ 0.06) and Ccl19 (Fig. 7a) at day 7 and an increase in Ifrd2 (Fig. 7c) at day 7 in the n-6 PUFA deprived fed animals after LPS administration, but they did not reach statistical significance $(p=0.07)$. Moreover, none of the groups differed significantly in expression of Ifngr2 (Fig. 7b), though a similar pattern of Ifrd 2 and $M f_{s} d 2 a$ expression was observed.

\section{Discussion}

This study is the first to perform a microarray in response to neuroinflammation and its resolution in relation to lowering dietary n-6 PUFA. Although mice consuming the n-6 PUFA deprived diet had lower body weight versus the adequate group at post-surgery day 14 , regardless of LPS administration, the magnitude of this difference was small and consistent with another report [12]. We saw an upregulation of pro-inflammatory and lipid-related genes after LPS administration, in agreement with previous studies $[6-8,26]$. Increasing pro- 


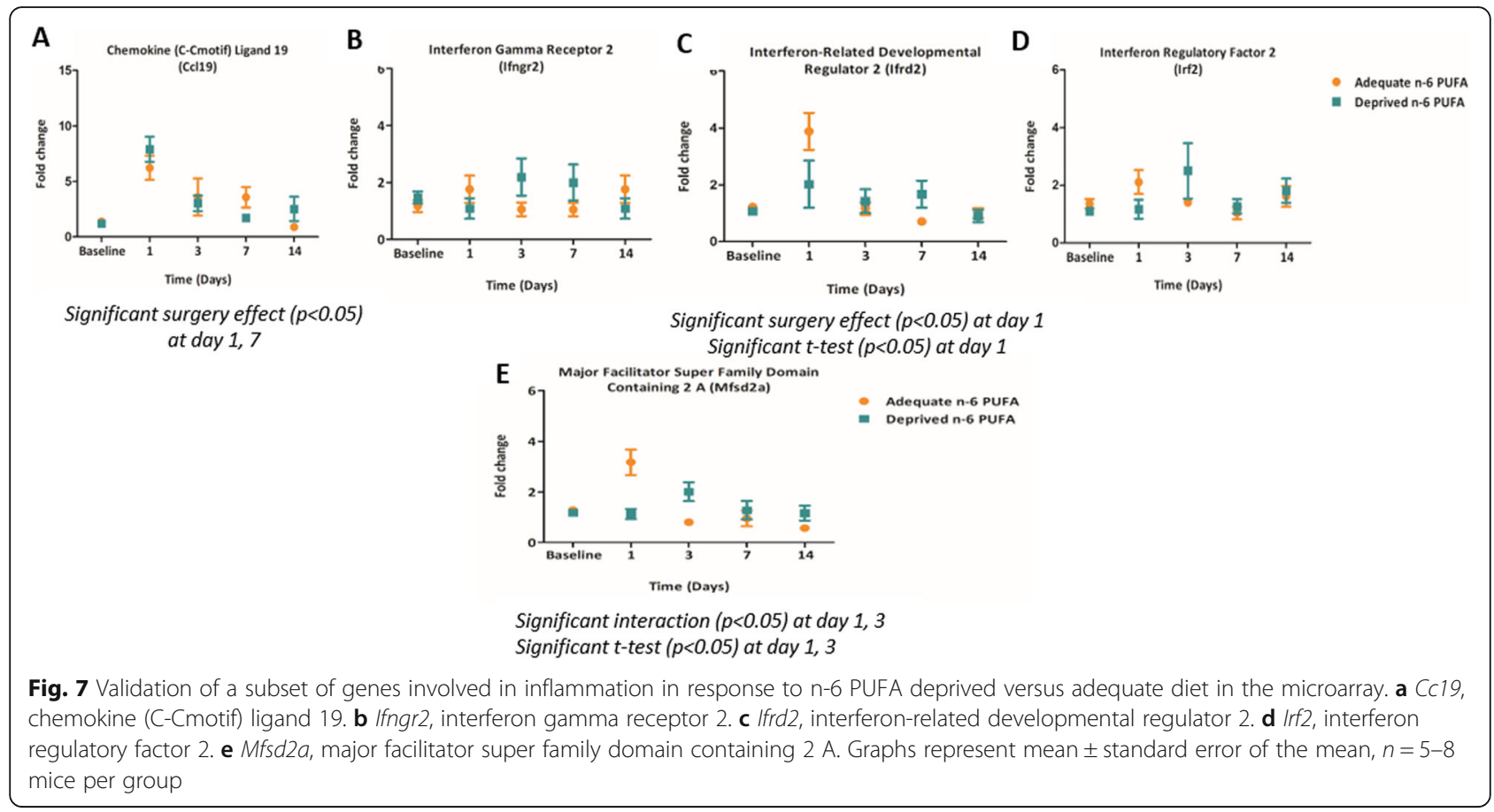

inflammatory gene expressions were associated with gene inflammation categories in response to icv administration of LPS. However, these pro-inflammatory markers were not reduced by lowering dietary n-6 PUFA as previously hypothesized. A recent review shows that in studies reporting an effect on the brain n-6 PUFA, LA accounted for on average $30 \%$ difference of dietary fatty acids between n-6 PUFA deprived and adequate diets [36]; the difference in LA levels between both diets in a study similar to what we report here was $\sim 20 \%$ [13], which may not be big enough to show major changes in inflammatory markers. Another possible reason for the minor changes in pro-inflammatory markers over time between diet groups is that the diet exposure ( $\sim 9$ weeks) is shorter compared to those of previous studies [26], which were about 15 weeks of intervention.

It has been proposed that DHA might exert protective effects in neuroinflammation, in part, via competition with ARA metabolism. Our current study, where we have previously reported brain ARA and lipid mediators are substantially decreased [13], does not support that lower ARA is robustly protective in neuroinflammation, albeit we cannot rule out an interaction between increased DHA and decreased ARA. In a previous work from our group, administering DHA or ARA icv suggested that DHA can exert anti-neuroinflammatory effects independent of ARA [8, 12, 24]. Interestingly, lowering n-6 PUFA from 7.4 to $2.4 \%$ of energy and increasing n-3 PUFA intake to $1.5 \mathrm{~g} /$ day for 12 weeks reduced headache frequency in chronic headache patients [37]. In these subjects, the frequency of headaches was positively associated with total linoleic acid concentrations and levels of pro-inflammatory mediators 8- and 9hydroxyeicosatetraenoic acids produced from ARA as well as 11-hydroxy-12,13-trans-epoxy-(9Z)-octadecenoate released from linoleic acid, in plasma [38, 39]. Although other inflammatory markers (cytokines, chemokines, microglia) have not been examined, Ramsden et al. demonstrated that increasing dietary n-3 PUFA concurrent with decreasing n- 6 PUFA has more pronounced effects in comparison to only lowering n-6 PUFA. In this present study, both diet treatments provide equal amounts of $n-3$ PUFA $\sim 3.4 \%$ of total fatty acids ( $\sim 4 \%$ of energy); thus, it might be another reason why lowering n-6 PUFA resulted in subtle changes in response to LPS administration. A previous study in rats reported that lowering n-6 PUFA reduced proinflammatory gene expression of Cox-2 and Pge 2 after LPS administration in brain [26], which was not observed in our study. However, there were many methodological differences between these studies.

Six genes that were selected for qPCR validation in response to LPS administration are either expressed on astrocytes (Gfap), both astrocytes and microglia (Fcgr1), lymphocytes $(L y 6 A)$, and inflammatory cytokines and chemokines (Irf7, Ccl12) or are involved in n-6 PUFA metabolism (Pla2g4a). All these genes, except Pla2g4a, were selected according to their enrichment effect in driving the Gene Ontology analysis including immune system process, innate immune response, and phagocytosis. The other five genes were based on the most significant uncorrected $p$ value from the microarray 
analysis in response to n-6 PUFA diet. Ifrd2, Ifngr2, Irf2, and $\mathrm{Ccl} 19$ are inflammatory cytokines and chemokines while Mfsd2a is thought to be a blood-brain barrier (BBB) transport protein [40]. Studies show that there is a positive correlation between the numbers of astrocytes and $M f s d 2 a$ expression in the brain [41]. Thus, it is possible that this upregulation of $M f s d 2 a$ in n-6 PUFA adequate fed mice is due to the high presence of astrocytes that maintain expression of Mfsd2a in the brain and control BBB homeostasis. The gene expression of Gfap has a similar trend of $M f s d 2 a$ expression as shown in microarray validation. Gfap had maximum expression at day 1 after LPS administration in the n- 6 PUFA adequate fed mice followed by high expression at day 3 post-surgery in the n-6 PUFA deprived group. Future studies in Mfsd2a knock-out mice are needed to fully understand the mechanism between n-6 PUFA and Mfsd2a gene expression in the brain. All the classical inflammatory markers related to microglia, cytokines, and chemokines in the microarray analysis were not significantly elevated according to the corrected $p$ value; however, the majority of them were statistically significant in response to LPS administration using a raw (uncorrected) $p$ value (see Additional file 1, Figure S3). However, the common genes associated with inflammation, such as Aif1 (iba1), Cd86, Cd68, Il-1ß, IL6ra, Tnfaip6, Ptgs2 (Cox-2), and Ccl5, in response to LPS administration were not used for validation because they did not drive the Gene Ontology enrichment (non-significant according to the corrected $p$ value); in addition, they were not driving the hierarchical clustering of samples, while in response to an n-6 PUFA diet, the expression of these inflammatory genes did not reach the raw $p$ value cutoffs $(<0.01)$, and thus were not used for validation.

The microarray study was hypothesis generating, seeking genes and gene expression categories that could be differentially affected by the diet groups in response to icv. Furthermore, the microarray was underpowered and caution must be taken when interpreting any results as null. In contrast, the validation study was hypothesis testing and was better powered to identify differences between the groups $(n=5-8)$. A limitation of this study is that the sample size is relatively small for microarray analysis and may not be enough to detect subtle changes induced by $\mathrm{n}-6$ PUFA diets, especially when using a corrected $p$ value. Using non-surgery animals as a control group is also another limitation, although we have previously reported that LPS induces a more robust inflammatory response than icv injection of vehicle [8]. Moreover, additional markers would be needed to make more comprehensive conclusions about dietary n-6 PUFA modulation and neuroinflammation. Another limitation of this work is that some markers are induced within hours $(\sim 8 \mathrm{~h})$ following LPS administration [7]; thus, it is possible that we may have missed changes in expression of some genes before day 1 of LPS administration.

\section{Conclusions}

The n-6 PUFA deprived diet modulated (both increased and decreased) the expression of some of the inflammatory genes, but it did not delay the resolution response to LPS relative to an n-6 PUFA adequate diet over the time course of inflammation. Although lowering n-6 PUFA have been shown in some human observational and animal studies to reduce inflammatory markers in the periphery, these effects were relatively minor in the hippocampus. Further research testing dietary n-6 PUFA modulation on a variety of brain inflammatory responses is required to determine the role of dietary $n-6$ PUFA in regulation of neuroinflammation.

\section{Supplementary information}

Supplementary information accompanies this paper at https://doi.org/10. 1186/s12974-019-1615-0.

\begin{abstract}
Additional file 1: Figure S1. Stability of various common reference (housekeeping) genes across diet/surgery groups. Glyceraldehyde 3phosphate dehydrogenase (Gapdh) and hypoxanthine guanine phosphoribosyltransferase (Hprt). Figures represent $n=5-8$ mice per group. Figure S2. Body weights of animals fed n-6 PUFA deprived versus n- 6 PUFA adequate before LPS administration and at 1, 3, 7 and 14 days after LPS administration. Bars represent mean \pm standard error of the mean of $n=7-8$ mice per group. Figure S3. Genes involved in the inflammatory response to LPS administration using a one-way ANOVA (corrected $p>0.05$ ) of the microarray. A) Aif1: allograft inflammatory factor 1, B) Cd86: cluster of differentiation 86 antigen, C) (d68: cluster of differentiation 68 antigen, D) IL-1 $\beta$ : interleukin 1 beta, E) IL-6ra: interleukin 6 receptor alpha chain, F) Tnfaip6: tumor necrosis factor alpha induced protein 6, G) Ptgs2 (Cox-2): prostaglandin-endoperoxide synthase 2 , and $\mathrm{H}) \mathrm{CCl}$ : chemokine ( $\mathrm{C}-\mathrm{C}$ motif) ligand 5. Bars represent mean \pm standard error of the mean of $n=3$ mice per group. Significant differences between LPS (day 1 and day 3 ) and baseline (non-surgery) groups are represented by * (raw $p<0.05$ ). Table S1. List of genes altered by (A) day 1 and (B) day 3 after LPS administration in each diet group. Figures represent $n=3$ mice per group. Table S2. List of significantly enriched gene ontology categories in (A) n-6 PUFA adequate and (B) n-6 PUFA deprived at day 3 LPS-administered compared to non-surgery mice. Based on $n=3$ mice per group. Benjamini Yekutieli false discovery rate (BY), Gene ontology (GO)
\end{abstract}

Additional file 2. The full microarray data (median centered) is presented in two-way ANOVA analysis. N-6 PUFA adequate and n-6 PUFA deprived diet groups at baseline, day 1 , and day 3 following LPS administration.

Additional file 3. The full microarray data (median centered) is presented in one-way ANOVA analysis. N-6 PUFA adequate and n-6 PUFA deprived diet groups at baseline, day 1 , and day 3 following LPS administration.

Additional file 4. An exploratory analysis of the candidate genes in response to the n-6 PUFA deprived versus adequate diet using Student's t-test of microarray data at baseline, day 1 , and day 3 following LPS administration.

\section{Abbreviations}

AD: Alzheimer's disease; ANOVA: Analysis of variance; ARA: Arachidonic acid; BBB: Blood-brain barrier; Ccl: Chemokine (c-c motif) ligand; Cd: Cluster of differentiation; Cox: Cyclooxygenase; CPLA 2 : Cytosolic phospholipase $\mathrm{A}_{2}$; DHA: Docosahexaenoic acid; Fcgr: High affinity immunoglobulin gamma Fc region; Gapdh: Glyceraldehyde 3-phosphate dehydrogenase; Gfap: Glial 
fibrillary acidic protein; Hprt: Hypoxanthine-guanine phosphoribosyltransferase; icv: Intracerebroventricular; Ifrd: Interferon-related developmental regulator; II: Interleukin; Irf: Interferon regulatory factor; LPS: Lipopolysaccharide; Ly: Lymphocyte antigen; Mfsd2a: Major facilitator superfamily domain containing 2A; PUFA: Polyunsaturated fatty acids; qPCR: Quantitative polymerase chain reaction; s.c.: Subcutaneous; SEM: Standard error of the mean; Tnf: Tumor necrosis factor; Trem: Triggering receptor expressed on myeloid cells

\section{Acknowledgements}

The microarray and its data analysis were performed at the Princess Margaret Genomics Centre, Toronto, ON, Canada. Dr. Amel Taibi (University of Toronto, Canada) assisted with the $\mathrm{qPCR}$ analysis.

\section{Authors' contributions}

RPB and SMA were responsible for the organization of structural and scientific background of this study. SMA conducted the bulk of the experimental work and analysis with assistance from LL and MT. SMA wrote the manuscript, and all authors read and approved the manuscript prior to submission.

\section{Funding}

This work was supported by a grant from the Canadian Institutes of Health Research (CIHR) to RPB. SMA holds King Abdul Aziz University Scholarship, LL was supported by the Ontario Student Opportunity Trust Fund and OGS, MT was supported by a NSERC CGS, and RPB holds a Canada Research Chair in Brain Lipid Metabolism. No funding agency was involved in the design, execution, or reporting of this study, beyond approving it for funding.

\section{Availability of data and materials}

Data and, where available, materials can be provided for non-commercial purposes upon request to the corresponding author.

\section{Ethics approval and consent to participate}

All animal procedures were carried out in the Department of Comparative Medicine at the University of Toronto in accordance with the Regulations of the Animals for Research Act in Ontario and the Guidelines of the Canadian Council on Animal Care (2017/18 protocol \# 20011827).

\section{Consent for publication}

\section{Not applicable.}

\section{Competing interests}

RPB has received research grants from Bunge Ltd., Arctic Nutrition, the Dairy Farmers of Canada, and Nestle Inc., as well as travel support from Mead Johnson and mass spectrometry equipment and support from Sciex. RPB is on the executive of the International Society for the Study of Fatty acids and Lipids and held a meeting on behalf of Fatty Acids and Cell Signalling, both of which rely on corporate sponsorship. RPB has given expert testimony in relation to supplements and the brain. RPB also provides complimentary fatty acid analysis for farmers, food producers, and others involved in the food industry, some of whom provide free food samples.

\section{Author details}

'Department of Clinical Nutrition, Faculty of Applied Medical Sciences, King Abdul Aziz University, Jeddah, Saudi Arabia. ${ }^{2}$ Department of Nutritional Sciences, Faculty of Medicine, University of Toronto, Toronto, ON, Canada.

\section{Received: 16 July 2019 Accepted: 9 October 2019}

\section{Published online: 27 November 2019}

\section{References}

1. Glass CK, Saijo K, Winner B, Marchetto MC, Gage FH. Mechanisms underlying inflammation in neurodegeneration. Cell. 2010;140:918-34.

2. Heneka MT, Carson MJ, Khoury JE, Landreth GE, Brosseron F, Feinstein DL, Jacobs AH, Wyss-Coray T, Vitorica J, Ransohoff RM, Herrup K, Frautschy SA, Finsen B, Brown GC, Verkhratsky A, Yamanaka K, Koistinaho J, Latz E, Halle A, Petzold GC, Town T, Morgan D, Shinohara ML, Perry VH, Holmes C, Bazan NG, Brooks DJ, Hunot S, Joseph B, Deigendesch N, Garaschuk O, Boddeke E, Dinarello CA, Breitner JC, Cole GM, Golenbock DT, Kummer MP. Neuroinflammation in Alzheimer's disease. Lancet Neurol. 2015;14:388-405.
3. Miller $\mathrm{AH}$, Raison $\mathrm{CL}$. The role of inflammation in depression: from evolutionary imperative to modern treatment target. Nat Rev Immunol. 2016;16:22-34

4. Li Q, Barres BA. Microglia and macrophages in brain homeostasis and disease. Nat Rev Immunol. 2018;18:225-42.

5. Ransohoff RM, Engelhardt B. The anatomical and cellular basis of immune surveillance in the central nervous system. Nat Rev Immunol. 2012;12:623-35.

6. Xia Y, Yamagata K, Krukoff TL. Differential expression of the CD14/TLR4 complex and inflammatory signaling molecules following icv administration of LPS. Brain Res. 2006:1095:85-95.

7. Trepanier MO, Hopperton KE, Giuliano V, Masoodi M, Bazinet RP. Increased brain docosahexaenoic acid has no effect on the resolution of neuroinflammation following intracerebroventricular lipopolysaccharide injection. Neurochem Int. 2018:118:115-26.

8. Orr SK, Palumbo S, Bosetti F, Mount HT, Kang JX, Greenwood CE, Ma DW, Serhan CN, Bazinet RP. Unesterified docosahexaenoic acid is protective in neuroinflammation. J Neurochem. 2013;127:378-93.

9. Griffin WS, Stanley LC, Ling C, White L, MacLeod V, Perrot LJ, White C3, Araoz C. Brain interleukin 1 and S-100 immunoreactivity are elevated in Down syndrome and Alzheimer disease. Proc Natl Acad Sci U S A. 1989;86: 7611-5.

10. Doorn KJ, Moors T, Drukarch B, van de Berg WD, Lucassen PJ, van Dam AM Microglial phenotypes and toll-like receptor 2 in the substantia nigra and hippocampus of incidental Lewy body disease cases and Parkinson's disease patients. Acta Neuropathol Commun. 2014;2:90-014-0090-1.

11. Dowlati Y, Herrmann N, Swardfager W, Liu H, Sham L, Reim EK, Lanctot KL. A meta-analysis of cytokines in major depression. Biol Psychiatry. 2010;67: 446-57.

12. Lin LE, Chen CT, Hildebrand KD, Liu Z, Hopperton KE, Bazinet RP. Chronic dietary n-6 PUFA deprivation leads to conservation of arachidonic acid and more rapid loss of DHA in rat brain phospholipids. J Lipid Res. 2015;56:390-402.

13. Alashmali SM, Kitson AP, Lin L, Lacombe RJS, Bazinet RP. Maternal dietary n6 polyunsaturated fatty acid deprivation does not exacerbate post-weaning reductions in arachidonic acid and its mediators in the mouse hippocampus. Nutr Neurosci. 2017;20:1-12.

14. Bazinet RP, Laye S. Polyunsaturated fatty acids and their metabolites in brain function and disease. Nat Rev Neurosci. 2014;15:771-85.

15. Bazan NG, Molina MF, Gordon WC. Docosahexaenoic acid signalolipidomics in nutrition: significance in aging, neuroinflammation, macular degeneration, Alzheimer's, and other neurodegenerative diseases. Annu Rev Nutr. 2011:31:321-51.

16. Vancassel S, Durand G, Barthelemy C, Lejeune B, Martineau J, Guilloteau D, Andres C, Chalon S. Plasma fatty acid levels in autistic children. Prostaglandins Leukot Essent Fatty Acids. 2001;65:1-7.

17. Maes M, Smith R, Christophe A, Cosyns P, Desnyder R, Meltzer H. Fatty acid composition in major depression: decreased omega 3 fractions in cholesteryl esters and increased C20: 4 omega 6/C20:5 omega 3 ratio in cholesteryl esters and phospholipids. J Affect Disord. 1996;38:35-46.

18. Esposito G, Giovacchini G, Liow JS, Bhattacharjee AK, Greenstein D, Schapiro M, Hallett M, Herscovitch P, Eckelman WC, Carson RE, Rapoport SI. Imaging neuroinflammation in Alzheimer's disease with radiolabeled arachidonic acid and PET. J Nucl Med. 2008:49:1414-21.

19. Sublette ME, Galfalvy HC, Hibbeln JR, Keilp JG, Malone KM, Oquendo MA, Mann JJ. Polyunsaturated fatty acid associations with dopaminergic indices in major depressive disorder. Int J Neuropsychopharmacol. 2014;17:383-91.

20. Morisseau C, Hammock BD. Impact of soluble epoxide hydrolase and epoxyeicosanoids on human health. Annu Rev Pharmacol Toxicol. 2013;53: 37-58.

21. Wu Y, Zhai H, Wang Y, Li L, Wu J, Wang F, Sun S, Yao S, Shang Y. Aspirintriggered lipoxin A (4) attenuates lipopolysaccharide-induced intracellular ROS in BV2 microglia cells by inhibiting the function of NADPH oxidase. Neurochem Res. 2012·37:1690-6.

22. Phillis JW, Horrocks LA, Farooqui AA. Cyclooxygenases, lipoxygenases, and epoxygenases in CNS: their role and involvement in neurological disorders. Brain Res Rev. 2006;52:201-43.

23. Wang X, Zhu M, Hjorth E, Cortes-Toro V, Eyjolfsdottir H, Graff C, Nennesmo I, Palmblad J, Eriksdotter M, Sambamurti K, Fitzgerald JM, Serhan CN, Granholm AC, Schultzberg M. Resolution of inflammation is altered in Alzheimer's disease. Alzheimers Dement. 2015;11:40-50.e1-2. 
24. Ramsden CE, Hennebelle M, Schuster S, Keyes GS, Johnson CD, Kirpich IA, Dahlen JE, Horowitz MS, Zamora D, Feldstein AE, McClain CJ, Muhlhausler BS, Makrides M, Gibson RA, Taha AY. Effects of diets enriched in linoleic acid and its peroxidation products on brain fatty acids, oxylipins, and aldehydes in mice. Biochim Biophys Acta Mol Cell Biol Lipids. 1863;2018:1206-13.

25. Kim HW, Rao JS, Rapoport SI, Igarashi M. Dietary n-6 PUFA deprivation downregulates arachidonate but upregulates docosahexaenoate metabolizing enzymes in rat brain. Biochim Biophys Acta. 1811;2011:111-7.

26. Taha AY, Blanchard HC, Cheon Y, Ramadan E, Chen M, Chang L, Rapoport SI. Dietary linoleic acid lowering reduces lipopolysaccharide-induced increase in brain arachidonic acid metabolism. Mol Neurobiol. 2016;54 4303-15.

27. Reeves PG, Nielsen FH, Fahey GC Jr. AIN-93 purified diets for laboratory rodents: final report of the American Institute of Nutrition ad hoc writing committee on the reformulation of the AIN-76A rodent diet. J Nutr. 1993; 123:1939-51.

28. Wene JD, Connor WE, DenBesten L. The development of essential fatty acid deficiency in healthy men fed fat-free diets intravenously and orally. J Clin Invest. 1975;56:127-34.

29. Collins FD, Sinclair AJ, Royle JP, Coats DA, Maynard AT, Leonard RF. Plasma lipids in human linoleic acid deficiency. Nutr Metab. 1971;13:150-67.

30. Guesnet P, Lallemand SM, Alessandri JM, Jouin M, Cunnane SC. alphaLinolenate reduces the dietary requirement for linoleate in the growing rat. Prostaglandins Leukot Essent Fatty Acids. 2011;85:353-60.

31. Hopperton KE, Trepanier MO, James NCE, Chouinard-Watkins R, Bazinet RP. Fish oil feeding attenuates neuroinflammatory gene expression without concomitant changes in brain eicosanoids and docosanoids in a mouse model of Alzheimer's disease. Brain Behav Immun. 2018;69:74-90.

32. Singh N, Shirdel EA, Waldron L, Zhang RH, Jurisica I, Comelli EM. The murine caecal microRNA signature depends on the presence of the endogenous microbiota. Int J Biol Sci. 2012;8:171-86.

33. Lopez-Gonzalez I, Schluter A, Aso E, Garcia-Esparcia P, Ansoleaga B, LLorens F, Carmona M, Moreno J, Fuso A, Portero-Otin M, Pamplona R, Pujol A, Ferrer I. Neuroinflammatory signals in Alzheimer disease and APP/PS1 transgenic mice: correlations with plaques, tangles, and oligomeric species. J Neuropathol Exp Neurol. 2015;74:319-44.

34. Venny. An Interactive Tool for Comparing Lists with Venn's Diagrams. 20072015; Available from: <http://bioinfogp.cnb.csic.es/tools/venny/index.html>. Accessed 15 Aug 2018.

35. Huang da W, Sherman BT, Lempicki RA. Systematic and integrative analysis of large gene lists using DAVID bioinformatics resources. Nat Protoc. 2009;4: 44-57.

36. Alashmali SM, Hopperton KE, Bazinet RP. Lowering dietary $n-6$ polyunsaturated fatty acids: interaction with brain arachidonic and docosahexaenoic acids. Curr Opin Lipidol. 2016;27:54-66.

37. Ramsden CE, Faurot KR, Zamora D, Suchindran CM, Macintosh BA, Gaylord S, Ringel A, Hibbeln JR, Feldstein AE, Mori TA, Barden A, Lynch C, Coble R, Mas E, Palsson O, Barrow DA, Mann JD. Targeted alteration of dietary n-3 and $n-6$ fatty acids for the treatment of chronic headaches: a randomized trial. Pain. 2013;154:2441-51.

38. Ramsden CE, Faurot KR, Zamora D, Palsson OS, Maclntosh BA, Gaylord S, Taha AY, Rapoport SI, Hibbeln JR, Davis JM, Mann JD. Targeted alterations in dietary $n-3$ and $n-6$ fatty acids improve life functioning and reduce psychological distress among patients with chronic headache: a secondary analysis of a randomized trial. Pain. 2015;156:587-96.

39. Ramsden CE, Domenichiello AF, Yuan ZX, Sapio MR, Keyes GS, Mishra SK, Gross JR, Majchrzak-Hong S, Zamora D, Horowitz MS, Davis JM, Sorokin AV, Dey A, LaPaglia DM, Wheeler JJ, Vasko MR, Mehta NN, Mannes AJ, ladarola MJ. A systems approach for discovering linoleic acid derivatives that potentially mediate pain and itch. Sci Signal. 2017;10:493-517.

40. Nguyen LN, Ma D, Shui G, Wong P, Cazenave-Gassiot A, Zhang X, Wenk MR, Goh EL, Silver DL. Mfsd2a is a transporter for the essential omega-3 fatty acid docosahexaenoic acid. Nature. 2014;509:503-6.

41. Tiwary S, Morales JE, Kwiatkowski SC, Lang FF, Rao G, McCarty JH. Metastatic brain tumors disrupt the blood-brain barrier and alter lipid metabolism by inhibiting expression of the endothelial cell fatty acid transporter Mfsd2a. Sci Rep. 2018:8:8267-80.

\section{Publisher's Note}

Springer Nature remains neutral with regard to jurisdictional claims in published maps and institutional affiliations.

Ready to submit your research? Choose BMC and benefit from:

- fast, convenient online submission

- thorough peer review by experienced researchers in your field

- rapid publication on acceptance

- support for research data, including large and complex data types

- gold Open Access which fosters wider collaboration and increased citations

- maximum visibility for your research: over $100 \mathrm{M}$ website views per year

At BMC, research is always in progress.

Learn more biomedcentral.com/submissions 